\title{
Cost Effective Media Optimization for the Enhanced Production of Hyaluronic Acid Using a Mutant Strain Streptococcus zooepidemicus 3523-7: A Statistical Approach
}

\author{
Seetha Ram Kotra ${ }^{1}$, T. C. Venkateswarulu², D. John Babu², Y. Sudheer ${ }^{3}$, K. \\ Seetharami Reddy ${ }^{3}$, J. B. Peravali ${ }^{4 *}$ and K. K. Pulicherla ${ }^{5}$ \\ ${ }^{1}$ Department of Biotechnology, Acharya Nagarjuna University, \\ Guntur-522510, India \\ ${ }^{2}$ School of Biotechnology, Vignan University, Guntur - 522213, India \\ ${ }^{3}$ Department of Biotechnology, R.V.R. \& J.C. College of Engineering, \\ Guntur-522019, India \\ ${ }^{4}$ Department of Biotechnology, Bapatla Engineering College, \\ Bapatla-522101, India \\ ${ }^{5}$ Advanced Center for Bioseparation Technology, VIT University, \\ Vellore-632014, Tamilnadu, India \\ *Corresponding author: jbperavali@gmail.com
}

\begin{abstract}
The hydrated gel hyaluronic acid (HA) comprises repeating units of glucuronic acid and $N$-acetylglucosamine. HA production has a lot of significance in the present day scenario owing to its clinical applications. Fermentative optimization is carried out in two steps. Statistical optimization of media components for the production of HA using Taguchi and Response Surface Methodology (RSM) was studied using a mutant strain Streptococcus zooepidemicus 3523-7. Initial optimization was carried out using $L_{27}$ orthogonal array. The significance of each factor with respect to HA production was identified using Taguchi design (Glucose, Yeast extract, $\mathrm{K}_{2} \mathrm{HPO}_{4}, \mathrm{NaH}_{2} \mathrm{PO}_{4}, \mathrm{NaCl}$, $\mathrm{NH}_{4} \mathrm{Cl}, 1 \mathrm{M} \mathrm{MgSO}{ }_{4}$ and Trace metal mix (TMM)) and the productivity was increased 1.34 folds (738 to $988 \mathrm{mg} / \mathrm{L}$ ) over native production medium. The outcome of Taguchi results indicates the glucose, yeast extract, $\mathrm{K}_{2} \mathrm{HPO}_{4}$ and $\mathrm{NH}_{4} \mathrm{Cl}$ are most influencing factors in the production of HA. Final optimization was carried out using RSM (Central Composite Rotatable Design) and the production was significantly enhanced to 1.4 folds (988 to $1386 \mathrm{mg} / \mathrm{L}$ ). For the first time statistical optimization was carried out using a mutant strain Streptococcus zooepidemicus 3523-7 and high yield $(1386 \mathrm{mg} / \mathrm{L})$ of HA was achieved.
\end{abstract}

Keywords: Hydrated gel, Fermentative optimization, Taguchi, Response Surface Methodology

\section{Introduction}

Hyaluronic acid (HA) contains repeated units of glucuronic acid and $\mathrm{N}$ acetylglucosamine, is naturally present in human body at higher concentrations throughout connective, epithelial, and neural tissues. Approximately, $0.22 \%$ of $\mathrm{HA}$ is present per kg weight in different human tissues viz., umbilical cord, dermis, serum, synovial fluid and in thoracic lymph. HA is used in the prevention and treatment of symptoms related to connective tissue disorders such as fractures, hernia, glaucoma, keratoconus, detached retina, osteoarthritis, TMJ, prevention of scarring, vocal cord repair insufficiency, wrinkled skin, cartilage damage, and wound and ligament healing. Of these, hyaluronic acid is extensively used in different joint disorders, including osteoarthritis. 
Different methods for treating osteoarthritis of knee include simple analgesics, intraarticular injection of glucocorticoids, weight-relieving braces, physiotherapy and total knee arthroplasty. Among all these intra-articular injection of hyaluronic acid, is a slowacting drug for the treatment of osteoarthritis [1]. Owing to its broad range of medical applications in biomedical and health care division hyaluronic acid attracted the attention of researchers. HA is conventionally extracted from animal tissues viz., synovial fluid, rooster combs and bovine vitreous humor [2-4]. But the production and purification of HA is economical. Hence, different types of microbes are used for the production of HA. Among all, different strains of group A and C Streptococci are used for the production of HA [5-9]. S. equi subsp. zooepidemicus MTCC 3523 is capable of producing exopolysaccharide, HA.

In this study, a mutant strain Streptococcus zooepidemicus 3523-7 is used for the production of HA using low cost medium. Based on the literature and best of our knowledge, the nutritional and environmental conditions for submerged culture of mutant Streptococcus zooepidemicus 3523-7 for HA production using statistical methods (Taguchi and RSM) has not been demonstrated. Initially, one-factor-at-a-time (classical method) was used to investigate the best media constituents such as carbon and nitrogen source. Later, concentration of the medium components was optimized using an orthogonal array and final optimization was carried out using RSM.

\section{Materials and Methods}

\subsection{Media Preparation and Culture Conditions}

All growth and production experiments were carried out in $500 \mathrm{ml}$ conical flasks with a working volume of $100 \mathrm{ml}$. The fermentation studies were carried out in production medium containing Glucose $-50 \mathrm{~g} / \mathrm{L}, \mathrm{K}_{2} \mathrm{HPO}_{4}-2 \mathrm{~g} / \mathrm{L}, \mathrm{KH}_{2} \mathrm{PO}_{4}-5 \mathrm{~g} / \mathrm{L}, \mathrm{NH}_{4} \mathrm{Cl}-0.5 \mathrm{~g} / \mathrm{L}$, Yeast extract $-5 \mathrm{~g} / \mathrm{L}, \mathrm{NaCl}-5 \mathrm{~g} / \mathrm{L}, \mathrm{MgSO}_{4}-0.5 \mathrm{~g} / \mathrm{L}, 1 \mathrm{M} \mathrm{CaCl}_{2}-0.1 \mathrm{~mL}, \mathrm{TMM}-1 \mathrm{~mL}$ $\left(\mathrm{Al}_{2}\left(\mathrm{SO}_{4}\right)_{3} \cdot 7 \mathrm{H}_{2} \mathrm{O}-10 \mathrm{mg} / \mathrm{L}, \mathrm{CuSO}_{4} \cdot \mathrm{H}_{2} \mathrm{O}-2 \mathrm{mg} / \mathrm{L}, \mathrm{H}_{3} \mathrm{BO}_{4}-1 \mathrm{mg} / \mathrm{L}, \mathrm{MnCl}_{3} \cdot 4 \mathrm{H}_{2} \mathrm{O}-20\right.$ $\mathrm{mg} / \mathrm{L}, \mathrm{NiCl}_{2} \cdot 6 \mathrm{H}_{2} \mathrm{O}-1 \mathrm{mg} / \mathrm{L}, \mathrm{Na}_{2} \mathrm{MoO}_{4} \cdot 2 \mathrm{H}_{2} \mathrm{O}-50 \mathrm{mg} / \mathrm{L}, \mathrm{ZnSO}_{4} .7 \mathrm{H}_{2} \mathrm{O}-50 \mathrm{mg} / \mathrm{L}, \mathrm{FeSO}_{4}$ $-50 \mathrm{mg} / \mathrm{L}$ ). The initial $\mathrm{pH}$ of the medium was adjusted to 7 before autoclaving at $121{ }^{0} \mathrm{C}$ for 15 to $20 \mathrm{~min}$. The sterile medium was inoculated aseptically with $5 \%$ of overnight fresh culture.

\subsection{Optimization of Production Medium Components using One-Factor-at-a-Time Classical Method}

2.2.1. Effect of Carbon Source: In the production medium, glucose was substituted with seven different carbon sources viz. sucrose, fructose, xylose, maltose, lactose, starch and galactose. All carbon sources were used at $5 \%$ concentration (w/v).

2.2.2. Effect of Nitrogen Source: In the production medium, yeast extract is substituted with different organic and inorganic nitrogen sources. Organic sources such as peptone, gelatin, soya peptone, meat peptone, mycological peptone, beef extract and corn steep liquor was used. Inorganic nitrogen sources such as potassium nitrate, diammonium hydrogen orthophosphate, sodium nitrate and ammonium nitrate were used. All nitrogen sources were used at $0.5 \%$ concentration $(\mathrm{w} / \mathrm{v})$.

2.2.3. Effect of Initial $\mathbf{p H}$ : The effect of initial $\mathrm{pH}$ of culture medium on production of $\mathrm{HA}$ was studied by varying the $\mathrm{pH}$ from $\mathrm{pH} 5-9$. The $\mathrm{pH}$ was adjusted using $0.1 \mathrm{~N}$ orthophosphoric acid (OPA) or $0.1 \mathrm{~N}$ sodium hydroxide $(\mathrm{NaOH})$. The initial $\mathrm{pH}$ which supports the maximum production of HA was used in further experiments. 
2.2.4. Effect of Fermentation Time: Production profile of HA was calculated after the one factor- at-a-time method. Measurement of total dry mass and HA production was done after every 12 hrs up to 48 hrs.

\subsection{Optimization of Concentrations of Production Medium Components using $\mathbf{L}_{27}$ - Orthogonal Array}

The design for the $\mathrm{L}_{27}$-orthogonal array was developed and analyzed using " $M I N I T A B$ 14.00" software. Table 1 depicted the fermentation conditions and the $\mathrm{L}_{27}$-orthogonal array was used in the present study. All experiments are performed in duplicates.

Table 1. $L_{27}$ - Orthogonal Design

\begin{tabular}{|c|c|c|c|c|c|c|c|c|c|c|c|}
\hline S. No & A & B & $\mathrm{C}$ & D & $\mathbf{E}$ & $\mathbf{F}$ & $\mathbf{G}$ & $\mathbf{H}$ & I & $\mathbf{P}_{1}{ }^{a}$ & $\mathbf{P}_{2}{ }^{\mathbf{a}}$ \\
\hline 1 & $\begin{array}{c}1 \\
(40)\end{array}$ & $\begin{array}{c}1 \\
(0.4)\end{array}$ & $\begin{array}{c}1 \\
(4.0)\end{array}$ & $\begin{array}{c}1 \\
(0.4)\end{array}$ & $\begin{array}{c}1 \\
(4.0)\end{array}$ & $\begin{array}{c}1 \\
(1.5)\end{array}$ & $\begin{array}{c}1 \\
(0.75)\end{array}$ & $\begin{array}{c}1 \\
(1.5)\end{array}$ & $1(75)$ & 659 & 668 \\
\hline 2 & $\begin{array}{c}1 \\
(40)\end{array}$ & $\begin{array}{c}1 \\
(0.4)\end{array}$ & $\begin{array}{c}1 \\
(4.0)\end{array}$ & $\begin{array}{c}1 \\
(0.4)\end{array}$ & $\begin{array}{c}2 \\
(5.0)\end{array}$ & $\begin{array}{c}2 \\
(2.0)\end{array}$ & $\begin{array}{c}2 \\
(1.00)\end{array}$ & $\begin{array}{c}2 \\
(2.0)\end{array}$ & $\begin{array}{c}2 \\
(100)\end{array}$ & 693 & 709 \\
\hline 3 & $\begin{array}{c}1 \\
(40) \\
\end{array}$ & $\begin{array}{c}1 \\
(0.4) \\
\end{array}$ & $\begin{array}{c}1 \\
(4.0) \\
\end{array}$ & $\begin{array}{c}1 \\
(0.4) \\
\end{array}$ & $\begin{array}{c}3 \\
(6.0) \\
\end{array}$ & $\begin{array}{c}3 \\
(2.5) \\
\end{array}$ & $\begin{array}{c}3 \\
(1.25) \\
\end{array}$ & $\begin{array}{c}3 \\
(2.5) \\
\end{array}$ & $\begin{array}{c}3 \\
(125) \\
\end{array}$ & 689 & 681 \\
\hline 4 & $\begin{array}{c}1 \\
(40)\end{array}$ & $\begin{array}{c}2 \\
(0.5)\end{array}$ & $\begin{array}{c}2 \\
(5.0)\end{array}$ & $\begin{array}{c}2 \\
(0.5)\end{array}$ & $\begin{array}{c}1 \\
(4.0)\end{array}$ & $\begin{array}{c}1 \\
(1.5)\end{array}$ & $\begin{array}{c}1 \\
(0.75)\end{array}$ & $\begin{array}{c}2 \\
(2.0)\end{array}$ & $\begin{array}{c}2 \\
(100)\end{array}$ & 705 & 709 \\
\hline 5 & $\begin{array}{c}1 \\
(40)\end{array}$ & $\begin{array}{c}2 \\
(0.5)\end{array}$ & $\begin{array}{c}2 \\
(5.0)\end{array}$ & $\begin{array}{c}2 \\
(0.5)\end{array}$ & $\begin{array}{c}2 \\
(5.0)\end{array}$ & $\begin{array}{c}2 \\
(2.0)\end{array}$ & $\begin{array}{c}2 \\
(1.00)\end{array}$ & $\begin{array}{c}3 \\
(2.5)\end{array}$ & $\begin{array}{c}3 \\
(125)\end{array}$ & 712 & 706 \\
\hline 6 & $\begin{array}{c}1 \\
(40)\end{array}$ & $\begin{array}{c}2 \\
(0.5)\end{array}$ & $\begin{array}{c}2 \\
(5.0)\end{array}$ & $\begin{array}{c}2 \\
(0.5)\end{array}$ & $\begin{array}{c}3 \\
(6.0)\end{array}$ & $\begin{array}{c}3 \\
(2.5)\end{array}$ & $\begin{array}{c}3 \\
(1.25)\end{array}$ & $\begin{array}{c}1 \\
(1.5)\end{array}$ & $1(75)$ & 708 & 701 \\
\hline 7 & $\begin{array}{c}1 \\
(40) \\
\end{array}$ & $\begin{array}{c}3 \\
(0.6) \\
\end{array}$ & $\begin{array}{c}3 \\
(6.0) \\
\end{array}$ & $\begin{array}{c}3 \\
(0.6) \\
\end{array}$ & $\begin{array}{c}1 \\
(4.0) \\
\end{array}$ & $\begin{array}{c}1 \\
(1.5) \\
\end{array}$ & $\begin{array}{c}1 \\
(0.75) \\
\end{array}$ & $\begin{array}{c}3 \\
(2.5) \\
\end{array}$ & $\begin{array}{c}3 \\
(125)\end{array}$ & 739 & 742 \\
\hline 8 & $\begin{array}{c}1 \\
(40)\end{array}$ & $\begin{array}{c}3 \\
(0.6)\end{array}$ & $\begin{array}{c}3 \\
(6.0)\end{array}$ & $\begin{array}{c}3 \\
(0.6)\end{array}$ & $\begin{array}{c}2 \\
(5.0)\end{array}$ & $\begin{array}{c}2 \\
(2.0)\end{array}$ & $\begin{array}{c}2 \\
(1.00)\end{array}$ & $\begin{array}{c}1 \\
(1.5)\end{array}$ & $1(75)$ & 724 & 735 \\
\hline 9 & $\begin{array}{c}1 \\
(40)\end{array}$ & $\begin{array}{c}3 \\
(0.6)\end{array}$ & $\begin{array}{c}3 \\
(6.0)\end{array}$ & $\begin{array}{c}3 \\
(0.6)\end{array}$ & $\begin{array}{c}3 \\
(6.0)\end{array}$ & $\begin{array}{c}3 \\
(2.5)\end{array}$ & $\begin{array}{c}3 \\
(1.25)\end{array}$ & $\begin{array}{c}2 \\
(2.0)\end{array}$ & $\begin{array}{c}2 \\
(100)\end{array}$ & 988 & 981 \\
\hline 10 & $\begin{array}{c}2 \\
(50)\end{array}$ & $\begin{array}{c}1 \\
(0.4)\end{array}$ & $\begin{array}{c}2 \\
(5.0)\end{array}$ & $\begin{array}{c}3 \\
(0.6)\end{array}$ & $\begin{array}{c}1 \\
(4.0)\end{array}$ & $\begin{array}{c}2 \\
(2.0)\end{array}$ & $\begin{array}{c}3 \\
(1.25)\end{array}$ & $\begin{array}{c}1 \\
(1.5)\end{array}$ & $\begin{array}{c}2 \\
(100)\end{array}$ & 936 & 324 \\
\hline 11 & $\begin{array}{c}2 \\
(50)\end{array}$ & $\begin{array}{c}1 \\
(0.4)\end{array}$ & $\begin{array}{c}2 \\
(5.0)\end{array}$ & $\begin{array}{c}3 \\
(0.6)\end{array}$ & $\begin{array}{c}2 \\
(5.0)\end{array}$ & $\begin{array}{c}3 \\
(2.5)\end{array}$ & $\begin{array}{c}1 \\
(0.75)\end{array}$ & $\begin{array}{c}2 \\
(2.0)\end{array}$ & $\begin{array}{c}3 \\
(125)\end{array}$ & 916 & 926 \\
\hline 12 & $\begin{array}{c}2 \\
(50)\end{array}$ & $\begin{array}{c}1 \\
(0.4)\end{array}$ & $\begin{array}{c}2 \\
(5.0)\end{array}$ & $\begin{array}{c}3 \\
(0.6)\end{array}$ & $\begin{array}{c}3 \\
(6.0)\end{array}$ & $\begin{array}{c}1 \\
(1.5)\end{array}$ & $\begin{array}{c}2 \\
(1.00)\end{array}$ & $\begin{array}{c}3 \\
(2.5)\end{array}$ & $1(75)$ & 948 & 952 \\
\hline 13 & $\begin{array}{c}2 \\
(50)\end{array}$ & $\begin{array}{c}2 \\
(0.5)\end{array}$ & $\begin{array}{c}3 \\
(6.0)\end{array}$ & $\begin{array}{c}1 \\
(0.4)\end{array}$ & $\begin{array}{c}1 \\
(4.0)\end{array}$ & $\begin{array}{c}2 \\
(2.0)\end{array}$ & $\begin{array}{c}3 \\
(1.25)\end{array}$ & $\begin{array}{c}2 \\
(2.0)\end{array}$ & $\begin{array}{c}3 \\
(125)\end{array}$ & 964 & 957 \\
\hline 14 & $\begin{array}{c}2 \\
(50)\end{array}$ & $\begin{array}{c}2 \\
(0.5)\end{array}$ & $\begin{array}{c}3 \\
(6.0)\end{array}$ & $\begin{array}{c}1 \\
(0.4)\end{array}$ & $\begin{array}{c}2 \\
(5.0)\end{array}$ & $\begin{array}{c}3 \\
(2.5)\end{array}$ & $\begin{array}{c}1 \\
(0.75)\end{array}$ & $\begin{array}{c}3 \\
(2.5)\end{array}$ & $1(75)$ & 953 & 959 \\
\hline 15 & $\begin{array}{c}2 \\
(50)\end{array}$ & $\begin{array}{c}2 \\
(0.5)\end{array}$ & $\begin{array}{c}3 \\
(6.0)\end{array}$ & $\begin{array}{c}1 \\
(0.4)\end{array}$ & $\begin{array}{c}3 \\
(6.0)\end{array}$ & $\begin{array}{c}1 \\
(1.5)\end{array}$ & $\begin{array}{c}2 \\
(1.00)\end{array}$ & $\begin{array}{c}1 \\
(1.5)\end{array}$ & $\begin{array}{c}2 \\
(100)\end{array}$ & 932 & 940 \\
\hline 16 & $\begin{array}{c}2 \\
(50) \\
\end{array}$ & $\begin{array}{c}3 \\
(0.6) \\
\end{array}$ & $\begin{array}{c}1 \\
(4.0) \\
\end{array}$ & $\begin{array}{c}2 \\
(0.5) \\
\end{array}$ & $\begin{array}{c}1 \\
(4.0)\end{array}$ & $\begin{array}{c}2 \\
(2.0) \\
\end{array}$ & $\begin{array}{c}3 \\
(1.25)\end{array}$ & $\begin{array}{c}3 \\
(2.5) \\
\end{array}$ & $1(75)$ & 956 & 964 \\
\hline 17 & $\begin{array}{c}2 \\
(50)\end{array}$ & $\begin{array}{c}3 \\
(0.6)\end{array}$ & $\begin{array}{c}1 \\
(4.0)\end{array}$ & $\begin{array}{c}2 \\
(0.5)\end{array}$ & $\begin{array}{c}2 \\
(5.0)\end{array}$ & $\begin{array}{c}3 \\
(2.5)\end{array}$ & $\begin{array}{c}1 \\
(0.75)\end{array}$ & $\begin{array}{c}1 \\
(1.5)\end{array}$ & $\begin{array}{c}2 \\
(100)\end{array}$ & 948 & 935 \\
\hline 18 & $\begin{array}{c}2 \\
(50)\end{array}$ & $\begin{array}{c}3 \\
(0.6)\end{array}$ & $\begin{array}{c}1 \\
(4.0)\end{array}$ & $\begin{array}{c}2 \\
(0.5)\end{array}$ & $\begin{array}{c}3 \\
(6.0)\end{array}$ & $\begin{array}{c}1 \\
(1.5)\end{array}$ & $\begin{array}{c}2 \\
(1.00)\end{array}$ & $\begin{array}{c}2 \\
(2.0)\end{array}$ & $\begin{array}{c}3 \\
(125)\end{array}$ & 967 & 958 \\
\hline 19 & $\begin{array}{c}3 \\
(60)\end{array}$ & $\begin{array}{c}1 \\
(0.4)\end{array}$ & $\begin{array}{c}3 \\
(6.0)\end{array}$ & $\begin{array}{c}2 \\
(0.5)\end{array}$ & $\begin{array}{c}1 \\
(4.0)\end{array}$ & $\begin{array}{c}3 \\
(2.5)\end{array}$ & $\begin{array}{c}2 \\
(1.00)\end{array}$ & $\begin{array}{c}1 \\
(1.5)\end{array}$ & $\begin{array}{c}3 \\
(125)\end{array}$ & 837 & 842 \\
\hline 20 & $\begin{array}{c}3 \\
(60)\end{array}$ & $\begin{array}{c}1 \\
(0.4)\end{array}$ & $\begin{array}{c}3 \\
(6.0)\end{array}$ & $\begin{array}{c}2 \\
(0.5)\end{array}$ & $\begin{array}{c}2 \\
(5.0)\end{array}$ & $\begin{array}{c}1 \\
(1.5)\end{array}$ & $\begin{array}{c}3 \\
(1.25)\end{array}$ & $\begin{array}{c}2 \\
(2.0)\end{array}$ & $1(75)$ & 864 & 872 \\
\hline 21 & $\begin{array}{c}3 \\
(60)\end{array}$ & $\begin{array}{c}1 \\
(0.4)\end{array}$ & $\begin{array}{c}3 \\
(6.0)\end{array}$ & $\begin{array}{c}2 \\
(0.5)\end{array}$ & $\begin{array}{c}3 \\
(6.0)\end{array}$ & $\begin{array}{c}2 \\
(2.0)\end{array}$ & $\begin{array}{c}1 \\
(0.75)\end{array}$ & $\begin{array}{c}3 \\
(2.5)\end{array}$ & $\begin{array}{c}2 \\
(100)\end{array}$ & 827 & 832 \\
\hline 22 & $\begin{array}{c}3 \\
(60) \\
\end{array}$ & $\begin{array}{c}2 \\
(0.5) \\
\end{array}$ & $\begin{array}{c}1 \\
(4.0) \\
\end{array}$ & $\begin{array}{c}3 \\
(0.6) \\
\end{array}$ & $\begin{array}{c}1 \\
(4.0) \\
\end{array}$ & $\begin{array}{c}3 \\
(2.5) \\
\end{array}$ & $\begin{array}{c}2 \\
(1.00) \\
\end{array}$ & $\begin{array}{c}2 \\
(2.0) \\
\end{array}$ & $1(75)$ & 871 & 882 \\
\hline 23 & $\begin{array}{c}3 \\
(60)\end{array}$ & $\begin{array}{c}2 \\
(0.5)\end{array}$ & $\begin{array}{c}1 \\
(4.0)\end{array}$ & $\begin{array}{c}3 \\
(0.6)\end{array}$ & $\begin{array}{c}2 \\
(5.0)\end{array}$ & $\begin{array}{c}1 \\
(1.5)\end{array}$ & $\begin{array}{c}3 \\
(1.25)\end{array}$ & $\begin{array}{c}3 \\
(2.5)\end{array}$ & $\begin{array}{c}2 \\
(100)\end{array}$ & 852 & 847 \\
\hline 24 & $\begin{array}{c}3 \\
(60)\end{array}$ & $\begin{array}{c}2 \\
(0.5)\end{array}$ & $\begin{array}{c}1 \\
(4.0)\end{array}$ & $\begin{array}{c}3 \\
(0.6)\end{array}$ & $\begin{array}{c}3 \\
(6.0)\end{array}$ & $\begin{array}{c}2 \\
(2.0)\end{array}$ & $\begin{array}{c}1 \\
(0.75)\end{array}$ & $\begin{array}{c}1 \\
(1.5)\end{array}$ & $\begin{array}{c}3 \\
(125)\end{array}$ & 839 & 846 \\
\hline
\end{tabular}




\begin{tabular}{|c|c|c|c|c|c|c|c|c|c|c|c|}
\hline 25 & $\begin{array}{c}3 \\
(60)\end{array}$ & $\begin{array}{c}3 \\
(0.6)\end{array}$ & $\begin{array}{c}2 \\
(5.0)\end{array}$ & $\begin{array}{c}1 \\
(0.4)\end{array}$ & $\begin{array}{c}1 \\
(4.0)\end{array}$ & $\begin{array}{c}3 \\
(2.5)\end{array}$ & $\begin{array}{c}2 \\
(1.00)\end{array}$ & $\begin{array}{c}3 \\
(2.5)\end{array}$ & $\begin{array}{c}2 \\
(100)\end{array}$ & 824 & 829 \\
\hline 26 & 3 & 3 & 2 & 1 & 2 & 1 & 3 & 1 & 3 & & \\
& $(60)$ & $(0.6)$ & $(5.0)$ & $(0.4)$ & $(5.0)$ & $(1.5)$ & $(1.25)$ & $(1.5)$ & $(125)$ & 804 & 812 \\
\hline 27 & 3 & 3 & 2 & 1 & 3 & 2 & 1 & 2 & & & \\
& $(60)$ & $(0.6)$ & $(5.0)$ & $(0.4)$ & $(6.0)$ & $(2.0)$ & $(0.75)$ & $(2.0)$ & $1(75)$ & 830 & 821 \\
\hline
\end{tabular}

A - Glucose (g/L), B - $\mathrm{NH}_{4} \mathrm{Cl}(\mathrm{g} / \mathrm{L}), \mathrm{C}-$ Yeast extract $(\mathrm{g} / \mathrm{L}), \mathrm{D}-\mathrm{MgSO}_{4}(\mathrm{~g} / \mathrm{L}), \mathrm{E}-\mathrm{NaCl}$ $(\mathrm{g} / \mathrm{L}), \mathrm{F}-\mathrm{KH}_{2} \mathrm{PO}_{4}(\mathrm{~g} / \mathrm{L}), \mathrm{G}-\mathrm{TMM}(\mathrm{mL}), \mathrm{H}-\mathrm{K}_{2} \mathrm{HPO}_{4}(\mathrm{~g} / \mathrm{L}), \mathrm{I}-1 \mathrm{M} \mathrm{CaCl}(\mu \mathrm{L})$.

$\mathrm{P}_{1}$ and $\mathrm{P}_{2}$ are production in $\mathrm{mg} / \mathrm{L}$.

Values in parentheses are uncoded values.

${ }^{a}$ Values are \pm of two independent experiments.

\subsection{Optimization of Concentrations of the Selected Medium Components by Central Composite Design}

To find out the combined effect of optimum concentration of four independent variables (a): Glucose (b): Yeast extract (c): $\mathrm{K}_{2} \mathrm{HPO}_{4}$ and (d): $\mathrm{NH}_{4} \mathrm{Cl}$ on maximum production of HA, media was optimized using Minitab. Four variables in the design were studied at five different levels, with all variables taken at a central coded value of zero. All the experiments were designed using the software, Design Expert Version 6.0.10 version (Stat Ease, Minneapolis, MN). The design expert gave (factorial portion $24=16$ with 8 star points) 24 plus 6 centre points leading to 30 experiments. The CCRD matrix in terms of coded and actual values of independent variables is given in Table 2 .

Table 2. The CCRD Matrix of Independent Variables in Coded form with their Corresponding Response from Experiments

\begin{tabular}{|c|c|c|c|c|c|c|c|c|}
\hline $\begin{array}{c}\text { Std } \\
\text { Order }\end{array}$ & $\begin{array}{l}\text { Run } \\
\text { Order }\end{array}$ & Block & $\begin{array}{c}\text { A } \\
(\mathrm{g} / \mathrm{L})\end{array}$ & $B(g / L)$ & $\begin{array}{c}\mathrm{C} \\
(\mathrm{g} / \mathrm{L})\end{array}$ & $\begin{array}{c}D \\
(g / L)\end{array}$ & $\begin{array}{c}\text { Experimental }^{\mathrm{a}} \\
(\mathrm{mg} / \mathrm{L})\end{array}$ & $\begin{array}{c}\text { Predicted } \\
(\mathrm{mg} / \mathrm{L})\end{array}$ \\
\hline 1 & 24 & $\begin{array}{c}\text { Block } \\
1\end{array}$ & $\begin{array}{c}-1 \\
(20.0)\end{array}$ & $-1(4.00)$ & $\begin{array}{c}-1 \\
(1.0)\end{array}$ & $\begin{array}{c}-1 \\
(1.0)\end{array}$ & 1063 & 1056.875 \\
\hline 2 & 20 & $\begin{array}{c}\text { Block } \\
1\end{array}$ & $\begin{array}{c}1 \\
(60.0)\end{array}$ & $-1(4.00)$ & $\begin{array}{c}-1 \\
(1.0)\end{array}$ & $\begin{array}{c}-1 \\
(1.0)\end{array}$ & 1124 & 1124.708333 \\
\hline 3 & 12 & $\begin{array}{c}\text { Block } \\
1 \\
\end{array}$ & $\begin{array}{c}-1 \\
(20.0) \\
\end{array}$ & $1(8.00)$ & $\begin{array}{c}-1 \\
(1.0) \\
\end{array}$ & $\begin{array}{c}-1 \\
(1.0) \\
\end{array}$ & 1286 & 1290.375 \\
\hline 4 & 23 & $\begin{array}{c}\text { Block } \\
1\end{array}$ & $\begin{array}{c}1 \\
(60.0) \\
\end{array}$ & $1(8.00)$ & $\begin{array}{c}-1 \\
(1.0)\end{array}$ & $\begin{array}{c}-1 \\
(1.0)\end{array}$ & 1288 & 1290.208333 \\
\hline 5 & 8 & $\begin{array}{c}\text { Block } \\
1 \\
\end{array}$ & $\begin{array}{c}-1 \\
(20.0)\end{array}$ & $-1(4.00)$ & $\begin{array}{c}1 \\
(3.0) \\
\end{array}$ & $\begin{array}{c}-1 \\
(1.0) \\
\end{array}$ & 1151 & 1148.708333 \\
\hline 6 & 22 & $\begin{array}{c}\text { Block } \\
1\end{array}$ & $\begin{array}{c}1 \\
(60.0)\end{array}$ & $-1(4.00)$ & $\begin{array}{c}1 \\
(3.0)\end{array}$ & $\begin{array}{c}-1 \\
(1.0)\end{array}$ & 1184 & 1184.041667 \\
\hline 7 & 16 & $\begin{array}{c}\text { Block } \\
1\end{array}$ & $\begin{array}{c}-1 \\
(20.0)\end{array}$ & $1(8.00)$ & $\begin{array}{c}1 \\
(3.0)\end{array}$ & $\begin{array}{c}-1 \\
(1.0)\end{array}$ & 1208 & 1208.208333 \\
\hline 8 & 29 & $\begin{array}{c}\text { Block } \\
1\end{array}$ & $\begin{array}{c}1 \\
(60.0) \\
\end{array}$ & $1(8.00)$ & $\begin{array}{c}1 \\
(3.0)\end{array}$ & $\begin{array}{c}-1 \\
(1.0) \\
\end{array}$ & 1185 & 1175.541667 \\
\hline 9 & 17 & $\begin{array}{c}\text { Block } \\
1\end{array}$ & $\begin{array}{c}-1 \\
(20.0)\end{array}$ & $-1(4.00)$ & $\begin{array}{c}-1 \\
(1.0) \\
\end{array}$ & $\begin{array}{c}1 \\
(5.0) \\
\end{array}$ & 1095 & 1096.708333 \\
\hline 10 & 14 & $\begin{array}{c}\text { Block } \\
1\end{array}$ & $\begin{array}{c}1 \\
(60.0)\end{array}$ & $-1(4.00)$ & $\begin{array}{c}-1 \\
(1.0)\end{array}$ & $\begin{array}{c}1 \\
(5.0)\end{array}$ & 1188 & 1194.041667 \\
\hline 11 & 6 & $\begin{array}{c}\text { Block } \\
1\end{array}$ & $\begin{array}{c}-1 \\
(20.0)\end{array}$ & $1(8.00)$ & $\begin{array}{c}-1 \\
(1.0)\end{array}$ & $\begin{array}{c}1 \\
(5.0)\end{array}$ & 1229 & 1235.208333 \\
\hline 12 & 18 & $\begin{array}{c}\text { Block } \\
1\end{array}$ & $\begin{array}{c}1 \\
(60.0)\end{array}$ & $1(8.00)$ & $\begin{array}{c}-1 \\
(1.0)\end{array}$ & $\begin{array}{c}1 \\
(5.0)\end{array}$ & 1270 & 1264.541667 \\
\hline 13 & 28 & $\begin{array}{c}\text { Block } \\
1\end{array}$ & $\begin{array}{c}-1 \\
(20.0)\end{array}$ & $-1(4.00)$ & $\begin{array}{c}1 \\
(3.0)\end{array}$ & $\begin{array}{c}1 \\
(5.0)\end{array}$ & 1305 & 1309.041667 \\
\hline 14 & 11 & $\begin{array}{c}\text { Block } \\
1\end{array}$ & $\begin{array}{c}1 \\
(60.0)\end{array}$ & $-1(4.00)$ & $\begin{array}{c}1 \\
(3.0)\end{array}$ & $\begin{array}{c}1 \\
(5.0)\end{array}$ & 1386 & 1373.875 \\
\hline 15 & 26 & $\begin{array}{c}\text { Block } \\
1\end{array}$ & $\begin{array}{c}-1 \\
(20.0)\end{array}$ & $1(8.00)$ & $\begin{array}{c}1 \\
(3.0)\end{array}$ & $\begin{array}{c}1 \\
(5.0)\end{array}$ & 1282 & 1273.541667 \\
\hline 16 & 2 & $\begin{array}{c}\text { Block } \\
1\end{array}$ & $\begin{array}{c}1 \\
(60.0)\end{array}$ & $1(8.00)$ & $\begin{array}{c}1 \\
(3.0)\end{array}$ & $\begin{array}{c}1 \\
(5.0)\end{array}$ & 1258 & 1270.375 \\
\hline
\end{tabular}




\begin{tabular}{|c|c|c|c|c|c|c|c|c|}
\hline 17 & 13 & $\begin{array}{c}\text { Block } \\
1\end{array}$ & $\begin{array}{c}-2 \\
(0.0)\end{array}$ & $0(6.00)$ & $\begin{array}{c}0 \\
(2.0)\end{array}$ & $\begin{array}{c}0 \\
(3.0)\end{array}$ & 1201 & 1200.416667 \\
\hline 18 & 10 & $\begin{array}{c}\text { Block } \\
1\end{array}$ & $\begin{array}{c}2 \\
(80.0)\end{array}$ & $0(6.00)$ & $\begin{array}{c}0 \\
(2.0)\end{array}$ & $\begin{array}{c}0 \\
(3.0)\end{array}$ & 1263 & 1265.083333 \\
\hline 19 & 30 & $\begin{array}{c}\text { Block } \\
1\end{array}$ & $\begin{array}{c}0 \\
(40.0)\end{array}$ & $\begin{array}{c}-2 \\
(2.00)\end{array}$ & $\begin{array}{c}0 \\
(2.0)\end{array}$ & $\begin{array}{c}0 \\
(3.0)\end{array}$ & 1090 & 1093.25 \\
\hline 20 & 27 & $\begin{array}{c}\text { Block } \\
1\end{array}$ & $\begin{array}{c}0 \\
(40.0)\end{array}$ & $\begin{array}{c}2 \\
(10.00)\end{array}$ & $\begin{array}{c}0 \\
(2.0)\end{array}$ & $\begin{array}{c}0 \\
(3.0)\end{array}$ & 1225 & 1223.25 \\
\hline 21 & 15 & $\begin{array}{c}\text { Block } \\
1\end{array}$ & $\begin{array}{c}0 \\
(40.0)\end{array}$ & $0(6.00)$ & $\begin{array}{c}-2 \\
(0.0)\end{array}$ & $\begin{array}{c}0 \\
(3.0)\end{array}$ & 1240 & 1234.416667 \\
\hline 22 & 9 & $\begin{array}{c}\text { Block } \\
1\end{array}$ & $\begin{array}{c}0 \\
(40.0)\end{array}$ & $0(6.00)$ & $\begin{array}{c}2 \\
(4.0)\end{array}$ & $\begin{array}{c}0 \\
(3.0)\end{array}$ & 1325 & 1332.083333 \\
\hline 23 & 1 & $\begin{array}{c}\text { Block } \\
1\end{array}$ & $\begin{array}{c}0 \\
(40.0)\end{array}$ & $0(6.00)$ & $\begin{array}{c}0 \\
(2.0)\end{array}$ & $\begin{array}{c}-2(-0) \\
1.0)\end{array}$ & 1128 & 1132.416667 \\
\hline 24 & 4 & $\begin{array}{c}\text { Block } \\
1\end{array}$ & $\begin{array}{c}0 \\
(40.0)\end{array}$ & $0(6.00)$ & $\begin{array}{c}0 \\
(2.0)\end{array}$ & $\begin{array}{c}2 \\
(7.0)\end{array}$ & 1270 & 1267.083333 \\
\hline 25 & 5 & $\begin{array}{c}\text { Block } \\
1\end{array}$ & $\begin{array}{c}0 \\
(40.0)\end{array}$ & $0(6.00)$ & $\begin{array}{c}0 \\
(2.0)\end{array}$ & $\begin{array}{c}0 \\
(3.0)\end{array}$ & 1048 & 1050 \\
\hline 26 & 7 & $\begin{array}{c}\text { Block } \\
1\end{array}$ & $\begin{array}{c}0 \\
(40.0)\end{array}$ & $0(6.00)$ & $\begin{array}{c}0 \\
(2.0)\end{array}$ & $\begin{array}{c}0 \\
(3.0)\end{array}$ & 1052 & 1050 \\
\hline 27 & 21 & $\begin{array}{c}\text { Block } \\
1\end{array}$ & $\begin{array}{c}0 \\
(40.0)\end{array}$ & $0(6.00)$ & $\begin{array}{c}0 \\
(2.0)\end{array}$ & $\begin{array}{c}0 \\
(3.0)\end{array}$ & 1049 & 1050 \\
\hline 28 & 3 & $\begin{array}{c}\text { Block } \\
1\end{array}$ & $\begin{array}{c}0 \\
(40.0)\end{array}$ & $0(6.00)$ & $\begin{array}{c}0 \\
(2.0)\end{array}$ & $\begin{array}{c}0 \\
(3.0)\end{array}$ & 1052 & 1050 \\
\hline 29 & 19 & $\begin{array}{c}\text { Block } \\
1\end{array}$ & $\begin{array}{c}0 \\
(40.0)\end{array}$ & $0(6.00)$ & $\begin{array}{c}0 \\
(2.0)\end{array}$ & $\begin{array}{c}0 \\
(3.0)\end{array}$ & 1048 & 1050 \\
\hline 30 & 25 & $\begin{array}{c}\text { Block } \\
1\end{array}$ & $\begin{array}{c}0 \\
(40.0)\end{array}$ & $0(6.00)$ & $\begin{array}{c}0 \\
(2.0)\end{array}$ & $\begin{array}{c}0 \\
(3.0)\end{array}$ & 1051 & 1050 \\
\hline
\end{tabular}

A - Glucose, B - Yeast extract, $\mathrm{C}-\mathrm{K}_{2} \mathrm{HPO}_{4}, \mathrm{D}-\mathrm{NH}_{4} \mathrm{Cl}$.

Values in parentheses are uncoded values.

Negative uncoded values in parentheses are set to be zero.

${ }^{a}$ Experiments are \pm of two independent experiments.

\subsection{Isolation of Hyaluronic Acid}

HA produced by mutant strain of S. zooepidemicus 3523-7 in fermentation broth was purified as described by Bitter and Muir in 1962 [10]. Carbazole method was used for improved recovery of HA and some modifications were carried out in purification steps. The production medium containing HA was precipitated using the addition of isopropyl alcohol [11]. After precipitation, the precipitated HA was redissolved in $0.15 \mathrm{M}$ sodium chloride and treated with activated charcoal $(0.5-2 \%)$. Later stirred for $45-60 \mathrm{~min}$ and allowed for centrifugation at 10,000 rpm for $30 \mathrm{~min}$ at $4^{\circ} \mathrm{C}$. After centrifugation, filtration was carried out using $0.45 \mu$ filters. The filtrate was further purified using ultrafiltration in diafiltration mode after two to three dilutions with sterile water. Finally the retentive containing HA sample was concentrated to original volume and precipitated with isopropyl alcohol and vacuum dried if necessary.

\section{Results and Discussion}

\subsection{One Factor-at-a-time Method}

The influence of different types of carbon and nitrogen sources on the production of HA by mutant Streptococcus zooepidemicus 3523-7 was grown in medium with continuous shaking. Individual experiments showed that glucose and yeast extract resulted the highest production of HA among different carbon and nitrogen sources tested.

3.1.1. Effect of Carbon Source: During fermentation, the carbon source act as major constituent for building the cellular material and also useful in production of HA. The 
effect of different carbon sources on production of HA was shown in Figure 1. The medium was supplemented with carbon sources such as sucrose, fructose, xylose, maltose, lactose, starch and galactose. Among all glucose is found to be promising in production of HA followed by fructose $(658 \mathrm{mg} / \mathrm{L})$. The culture was able to grow in all carbon sources (sucrose, fructose, xylose, maltose, lactose, starch and galactose), but HA was production is very low in xylose $(253 \mathrm{mg} / \mathrm{L})$. In another studies, carbon sources like starch, lactose, dextrin and sucrose can be used for HA production which is similar to glucose [12, 13]. Chong et al., in 2005 used maltose (20 g/L) as carbon source using $S$. equi subsp zooepidemicus (ATCC 35246) by batch fermentation mode [14]. Armstrong \& Johns in 1997 used glucose $(60 \mathrm{~g} / \mathrm{L})$ as carbon sources using S. equi subsp zooepidemicus (ATCC 35246) [15].

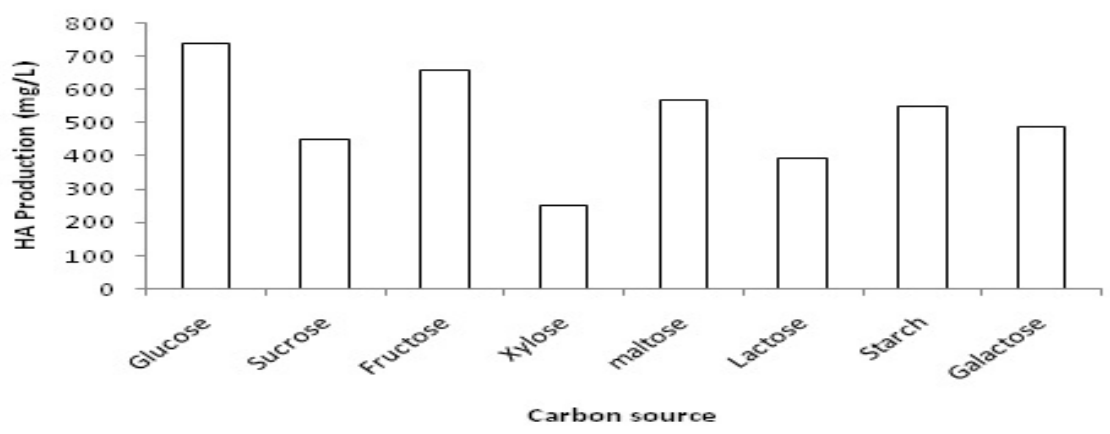

Figure 1. Effect of Different Carbon Sources on HA Production by Mutant Streptococcus Zooepidemicus 3523-7

3.1.2. Effect of Nitrogen Source: Different types of nitrogen sources (organic and inorganic) were evaluated for their effect on growth and production of HA was shown in Figure 2. Yeast extract was the best organic nitrogen source and sodium nitrate was found to be the best inorganic nitrogen source for the production of HA. Out of eleven nitrogen sources (peptone, gelatin, soya peptone, meat peptone, mycological peptone, beef extract, corn steep liquor, potassium nitrate, diammonium hydrogen orthophosphate, sodium nitrate and ammonium nitrate), yeast extract gave the maximum yield of $788 \mathrm{mg} / \mathrm{L}$ followed by production using beef extract $(712 \mathrm{mg} / \mathrm{L})$. With glucose as the carbon source, maximum HA production was achieved with yeast extract at concentration of $0.5 \%$. In another study also yeast-derived nitrogen source (YE 0251) showed the highest HA production [16, 17]. Vazquez et al., in 2010 used tuna peptone $(8 \mathrm{~g} / \mathrm{L})$ for the production of HA using S. equi subsp zooepidemicus (ATCC 35246) by fermentation mode [18].

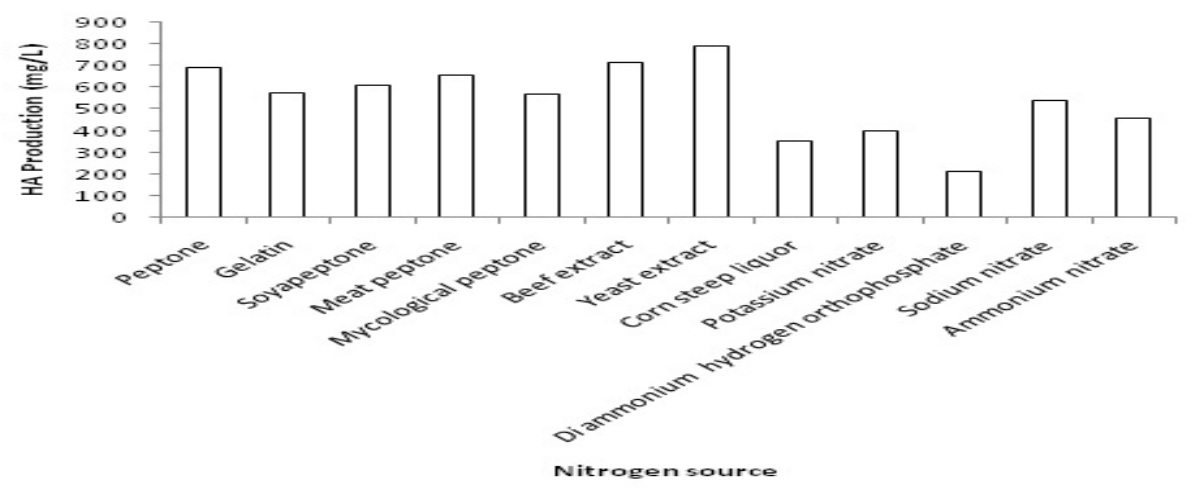

Figure 2. Effect of Different Nitrogen Sources on HA Production by Mutant Streptococcus Zooepidemicus 3523-7 
3.1.3. Effect of Fermentation Time: The effect of cultivation time on HA production under optimum conditions were showed in Figure 3. Results indicating $24 \mathrm{hr}$ is required for maximum production. After 24 hrs, total protein content and enzyme activity was decreased significantly.

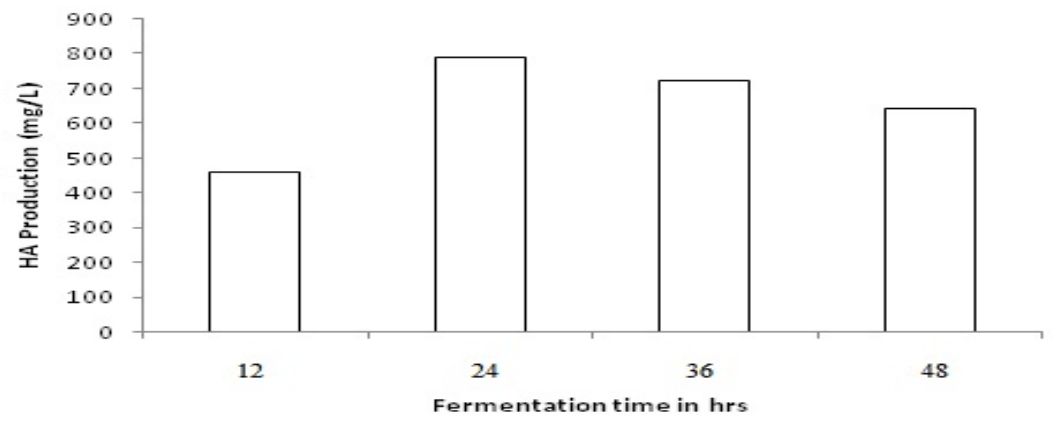

Figure 3. Effect of Cultivation Time on Production of HA by Mutant Streptococcus Zooepidemicus 3523-7

3.1.4. Effect of pH: Figure 4 shows the effect of $\mathrm{pH}$ for the production of biomass and $\mathrm{HA}$ at different $\mathrm{pH}$ and 7 is the ideal $\mathrm{pH}$ for the over production of biomass and enzyme production. Both in acidic and basic $\mathrm{pH}$ the production levels are reduced. The results in this study are similar to the results of Long et al., 2011 [19].

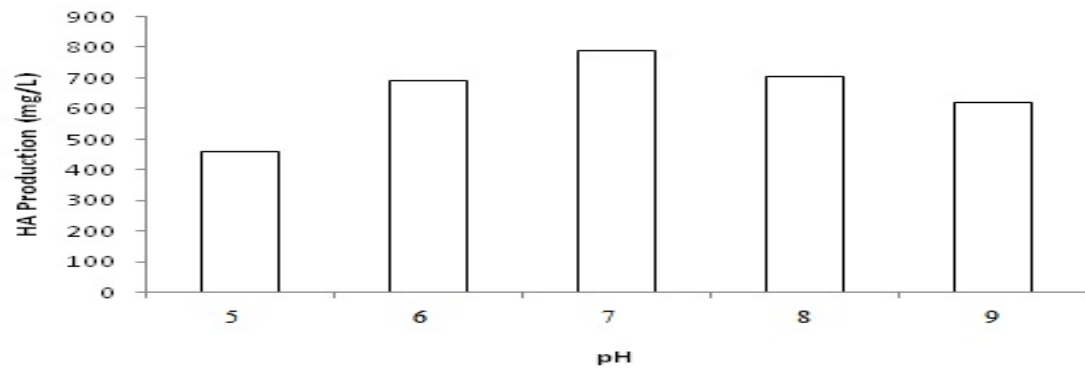

Figure 4. Effect of pH on Production of HA by Mutant Streptococcus Zooepidemicus 3523-7

\subsection{Optimization using $L_{27}-$ orthogonal Array}

After the selection of best carbon and nitrogen sources, the medium was subjected to initial optimization using $\mathrm{L}_{27}$ - orthogonal array. The parameters optimized involved concentrations of Glucose, $\mathrm{NH}_{4} \mathrm{Cl}$, Yeast extract, $\mathrm{MgSO}_{4}, \mathrm{NaCl}, \mathrm{KH}_{2} \mathrm{PO}_{4}, \mathrm{TMM}, \mathrm{K}_{2} \mathrm{HPO}_{4}$, $1 \mathrm{M} \mathrm{CaCl}_{2}$. Table 3 represents the response table for means (larger is better) obtained with $\mathrm{L}_{27}$-orthogonal array. Table 4 represents the response table for signal to noise ratio (larger is better) obtained with $\mathrm{L}_{27}$-orthogonal array. The last two rows in Tables 3 and 4 documents the delta values and ranks for the system. These delta values and ranks helps to assess which factors have the greatest effect on the response. Delta was measured by taking the difference between the highest and lowest characteristic average for a factor and higher delta value indicates greater effect of that component. On the other hand rank orders the factors from the greatest effect (based on the delta values) to the least effect on the response. The order in which the individual components selected in the present study effect the fermentation process can be ranked as glucose $>$ yeast extract $>\mathrm{K}_{2} \mathrm{HPO}_{4}>$ $\mathrm{NH} 4 \mathrm{Cl}>\mathrm{KH} 2 \mathrm{PO} 4>\mathrm{NaCl}>\mathrm{MgSO} 4>1 \mathrm{M} \mathrm{CaCl} 2>$ Trace metal mix $(\mathrm{TMM})$ suggesting that glucose had a major effect and Trace metal mix (TMM) had least effect on HA production by mutant Streptococcus zooepidemicus 3523-7. 
Table 3. Response Table for Means

\begin{tabular}{|c|c|c|c|c|c|c|c|c|c|}
\hline Level & Glucose & $\mathbf{N H}_{\mathbf{4}} \mathbf{C l}$ & $\begin{array}{c}\text { Yeast } \\
\text { extract }\end{array}$ & $\mathbf{M g S O}_{\mathbf{4}}$ & $\mathbf{N a C l}$ & $\mathbf{K H}_{\mathbf{2}} \mathbf{P O}_{\mathbf{4}}$ & $\mathbf{T M M}$ & $\begin{array}{c}\mathbf{K}_{\mathbf{2}} \mathbf{H P} \\
\mathbf{O}_{\mathbf{4}}\end{array}$ & $\begin{array}{c}\mathbf{1 M} \\
\mathbf{C a C l}_{\mathbf{2}}\end{array}$ \\
\hline 1 & 736.1 & 787.5 & 831.3 & 818.0 & 800.4 & 831.7 & 825.2 & 788.3 & 837.1 \\
\hline 2 & 913.1 & 837.9 & 786.8 & 835.7 & 831.5 & 798.6 & 836.7 & 867.4 & 822.8 \\
\hline 3 & 840.6 & 864.3 & 871.6 & 836.0 & 857.8 & 859.4 & 827.8 & 834.0 & 829.8 \\
\hline Delta & 177.0 & 76.8 & 84.7 & 18.0 & 57.3 & 60.8 & 11.5 & 79.1 & 14.2 \\
\hline Rank & 1 & 4 & 2 & 7 & 6 & 5 & 9 & 3 & 8 \\
\hline
\end{tabular}

Table 4. Response Table for S/N Ratio

\begin{tabular}{|c|c|c|c|c|c|c|c|c|c|}
\hline Level & Glucose & $\mathbf{N H}_{\mathbf{4}} \mathbf{C l}$ & $\begin{array}{c}\text { Yeast } \\
\text { extract }\end{array}$ & $\mathbf{M g S O}_{\mathbf{4}}$ & $\mathbf{N a C l}$ & $\begin{array}{c}\mathbf{K H}_{\mathbf{2}} \mathbf{P} \\
\mathbf{O}_{\mathbf{4}}\end{array}$ & $\mathbf{T M M}$ & $\mathbf{K}_{\mathbf{2}} \mathbf{H P O}_{\mathbf{4}}$ & $\begin{array}{c}\mathbf{1 M} \\
\mathbf{C a C l}_{\mathbf{2}}\end{array}$ \\
\hline 1 & 57.28 & 57.47 & 58.31 & 58.17 & 57.61 & 58.33 & 58.27 & 57.49 & 58.38 \\
\hline 2 & 58.78 & 58.40 & 57.48 & 58.37 & 58.34 & 57.60 & 58.39 & 58.70 & 57.86 \\
\hline 3 & 58.49 & 58.68 & 58.76 & 58.00 & 58.60 & 58.62 & 57.90 & 58.36 & 58.32 \\
\hline Delta & 1.50 & 1.21 & 1.27 & 0.37 & 0.99 & 1.02 & 0.49 & 1.21 & 0.52 \\
\hline Rank & 1 & 4 & 2 & 9 & 6 & 5 & 8 & 3 & 7 \\
\hline
\end{tabular}

Figures 5 and 6 represent the main effect plots for the system and show how each factor affects the response. MINITAB creates the main effects plot by plotting the characteristic average for each factor level and the averages are the same as those displayed in the response Table 1 . When the line is horizontal (parallel to the $\mathrm{x}$-axis), then there is no main effect. Each level of the factor affects the characteristic in the same way and the characteristic average is the same across all factor levels. When the line is not horizontal (parallel to the x-axis), then there is a main effect present. Different levels of the factor affect the characteristic differently. The greater the difference in the vertical position of the plotted points (the greater the deviation from the parallel $\mathrm{x}$-axis), the greater is the magnitude of the main effect.

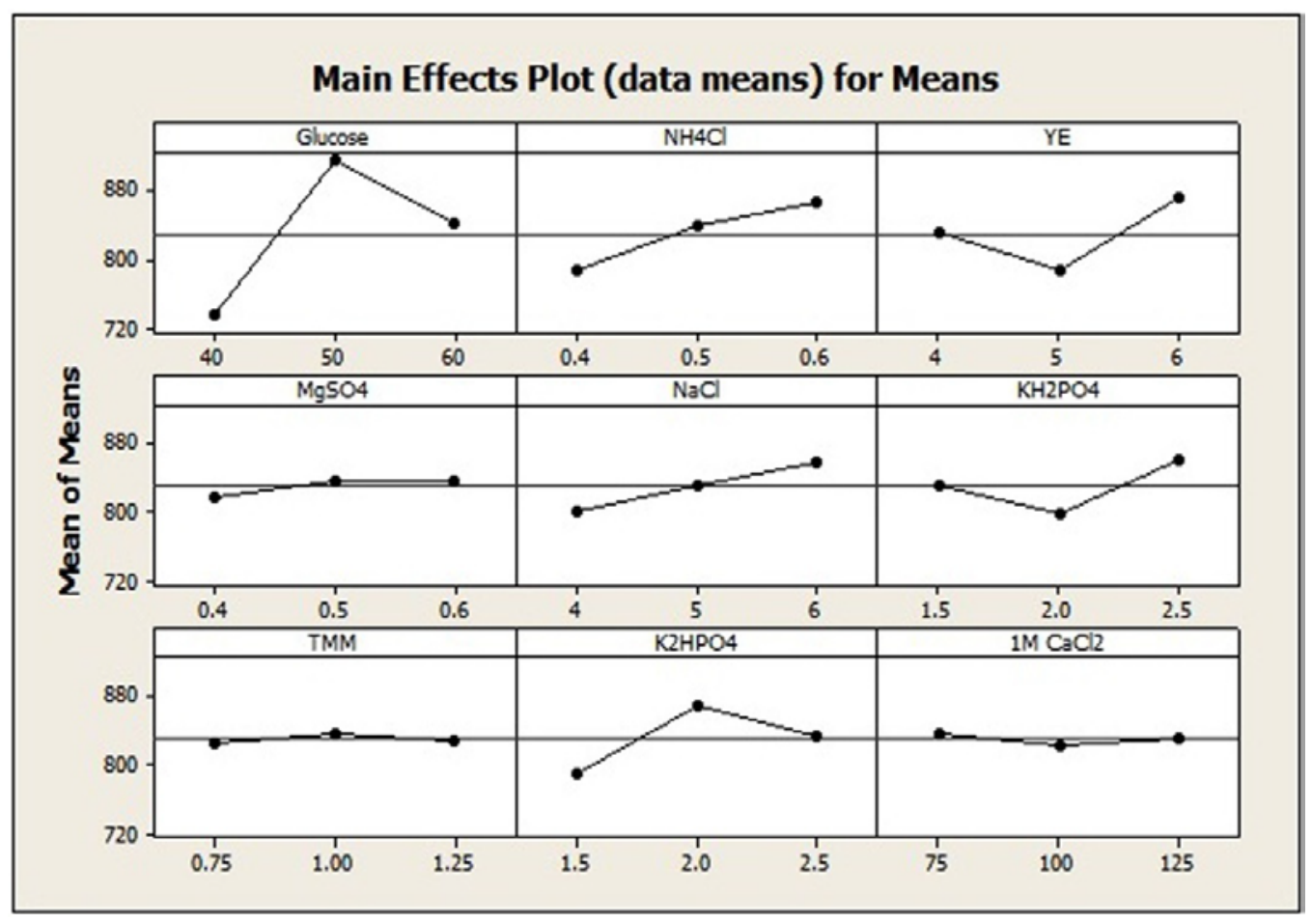

Figure 5. Main Effects Plot for Means 


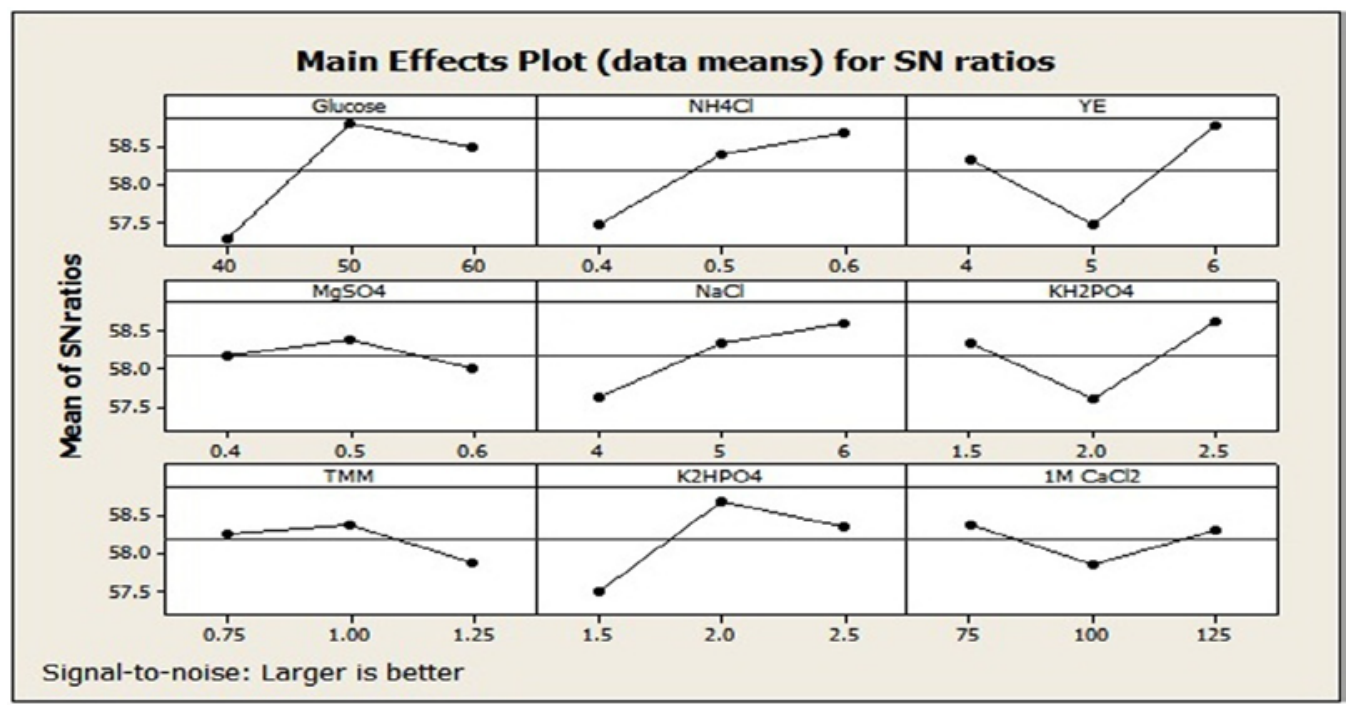

Figure 6. Main Effects Plot for S/N Ratio

\subsection{Optimization of Concentrations of the Selected Medium Components by RSM}

The combined effect of four independent variables A: Glucose; B: Yeast extract; C: $\mathrm{K}_{2} \mathrm{HPO}_{4}$; D: $\mathrm{NH}_{4} \mathrm{Cl}$; for production of HA was examined using RSM. The CCRD gave quadratic model for experimental results. The following equations represent the mathematical model relating the production of HA with independent process variables, A to $\mathrm{D}$ and the second order polynomial coefficient for each term of the equation determined through multiple regression analysis using the Design Expert 6.0.10.

Final equation in terms of coded factors for the production of HA $(\mathrm{mg} / \mathrm{L})$ was $1050+$ 16.17 X A + 32.50 X B + 24.42 X C + 33.67 X D + 45.69 X A ${ }^{2}+27.06 \mathrm{X} \mathrm{B}^{2}+58.31 \mathrm{X}$ $\mathrm{C}^{2}+37.44 \mathrm{X} \mathrm{D}^{2}-17$ X A X B -8.12 X A X C + 7.38 X A X D - 43.5 X B X C -23.75 X $\mathrm{B}$ X D + 30.13 X C X D.

Final equation in terms of actual factors for the production of $\mathrm{HA}(\mathrm{mg} / \mathrm{L})$ was $1174.75521-5.51979 \mathrm{X}$ glucose $+13.375 \mathrm{X}$ yeast extract $-107.27083 \mathrm{X} \mathrm{K}_{2} \mathrm{HPO}_{4}-$ $41.19792 \mathrm{X} \mathrm{NH}_{4} \mathrm{Cl}+0.11422 \mathrm{X}$ (glucose) $^{2}+6.76562 \mathrm{X}$ (yeast extract) ${ }^{2}+58.31250 \mathrm{X}$ $\left(\mathrm{K}_{2} \mathrm{HPO}_{4}\right)^{2}+9.35938 \mathrm{X}\left(\mathrm{NH}_{4} \mathrm{Cl}\right)^{2}-0.42500 \mathrm{X}$ glucose $\mathrm{X}$ yeast extract $-0.40625 \mathrm{X}$

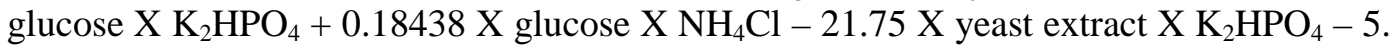
$93750 \mathrm{X}$ yeast extract $\mathrm{X} \mathrm{NH} 4 \mathrm{Cl}+15.0625 \mathrm{X} \mathrm{K}_{2} \mathrm{HPO}_{4} \mathrm{X} \mathrm{NH}_{4} \mathrm{Cl}$.

The experimental and predicted values of yields of $\mathrm{HA}$ are given in Table 2. The results were analyzed by using ANOVA, i.e., analysis of variance suitable for the experimental design used. The ANOVA of the quadratic model indicated that the model is significant. The model F-value of 384.6 implies the model to be significant and is calculated as ratio of mean square regression and mean square residual. Model P-value (Prob $>$ F) was very low $(<0.0001)$, again signifying the model to be significant. The $\mathrm{P}$ values were used as a tool to check the significance of each of the coefficients, which, in turn are necessary to understand the pattern of the mutual interactions between the test variables. The smaller the magnitude of the $\mathrm{P}$, the more significant is the corresponding coefficient. Values of $\mathrm{p}$ less than 0.05 indicate the model terms to be significant. The coefficient estimates and the corresponding $\mathrm{P}$ values suggests that, among the test variables used in the study, $A, B, C, D, A^{2}, B^{2}, C^{2}, D^{2}, A B, A C, A D, B C, B D$ and $C D$ (where $\mathrm{A}=$ Glucose $\mathrm{B}=$ Yeast extract, $\mathrm{C}=\mathrm{K}_{2} \mathrm{HPO}_{4}$ and $\mathrm{D}=\mathrm{NH}_{4} \mathrm{Cl}$ ) are significant model.

The fit of the model was also expressed by the coefficient of regression $\left(\mathrm{R}^{2}\right)$, which was found to be 0.9972 , indicating that $99.72 \%$ of the confidence level of the model to predict the response (HA yield). The "Pred R-Squared" of 0.9843 is in reasonable 
agreement with the "Adj R-Squared” of 0.9946. “Adeq Precision” measures the signal to noise ratio. A ratio greater than 4 is desirable. Here, the ratio of 62.787 indicates an adequate signal. In RSM, contour plot generation and point prediction were also studied to find optimum value of the combination of the four media constitutes for the over production of HA. The values (predicted) are verified with experimental results.

The three-dimensional graphs were generated for the pair-wise combination of the four factors, while keeping the other two at their center point levels (Figure 7-12). From the central point of the contour plot or from the bump of the 3D plot the optimal composition of medium components was identified. Figure 13 illustrated the parity plot for the distribution of predicted and experimental values for the production of HA.

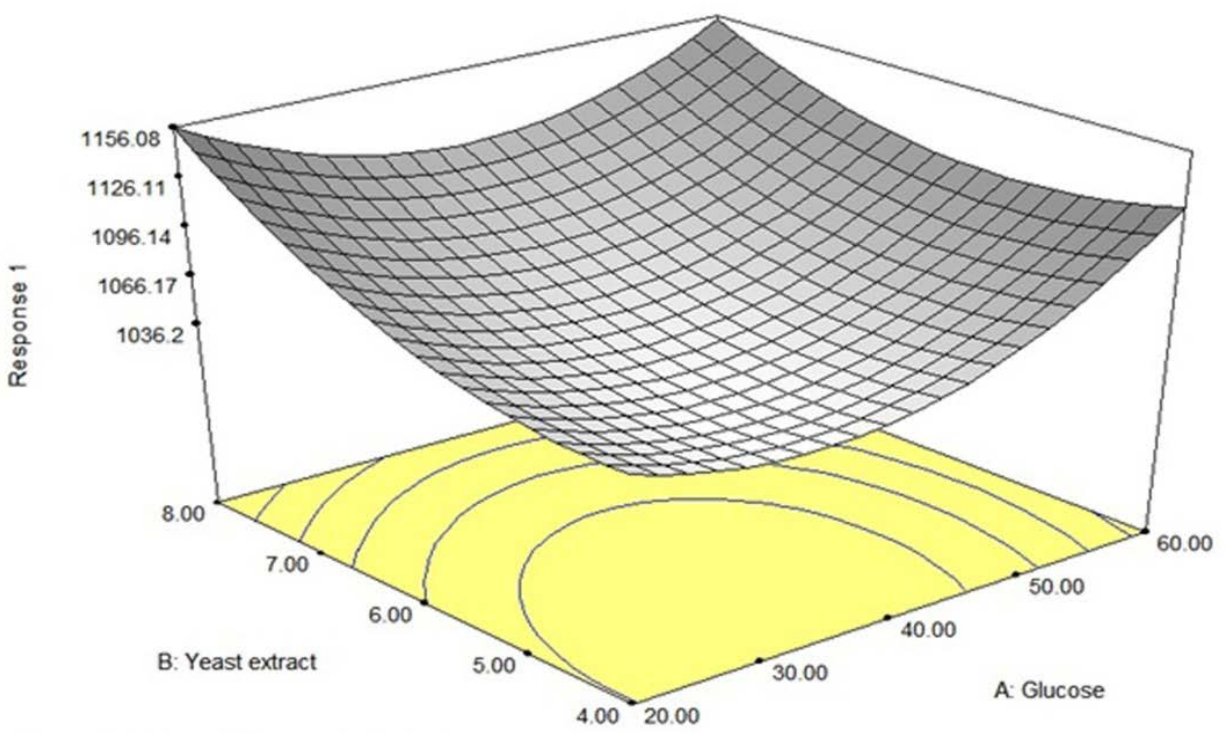

Figure 7. Illustrated the Response Surface Plot for Production of HA; Effect of Glucose and Yeast Extract

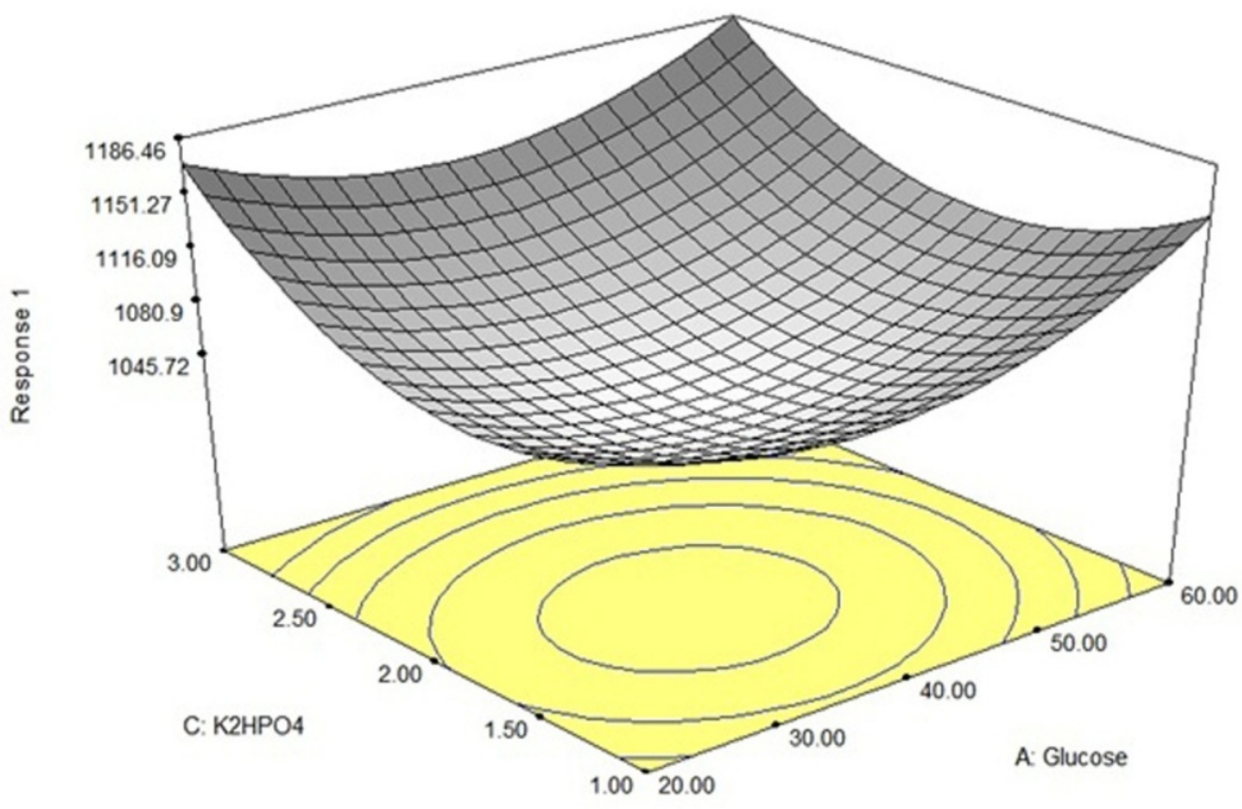

Figure 8. Illustrated the Response Surface Plot for Production of HA; Effect of Glucose and $\mathrm{K}_{2} \mathrm{HPO}_{4}$ 


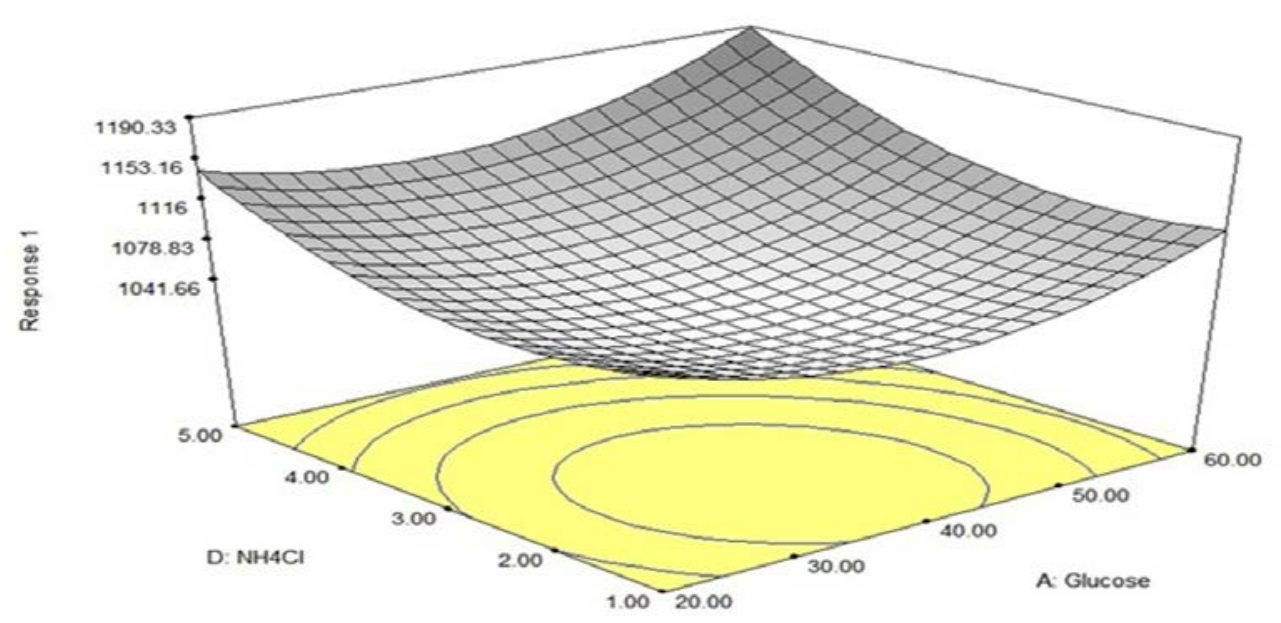

Figure 9. Illustrated the Response Surface Plot for Production of HA; Effect of Glucose and $\mathrm{NH}_{4} \mathrm{Cl}$

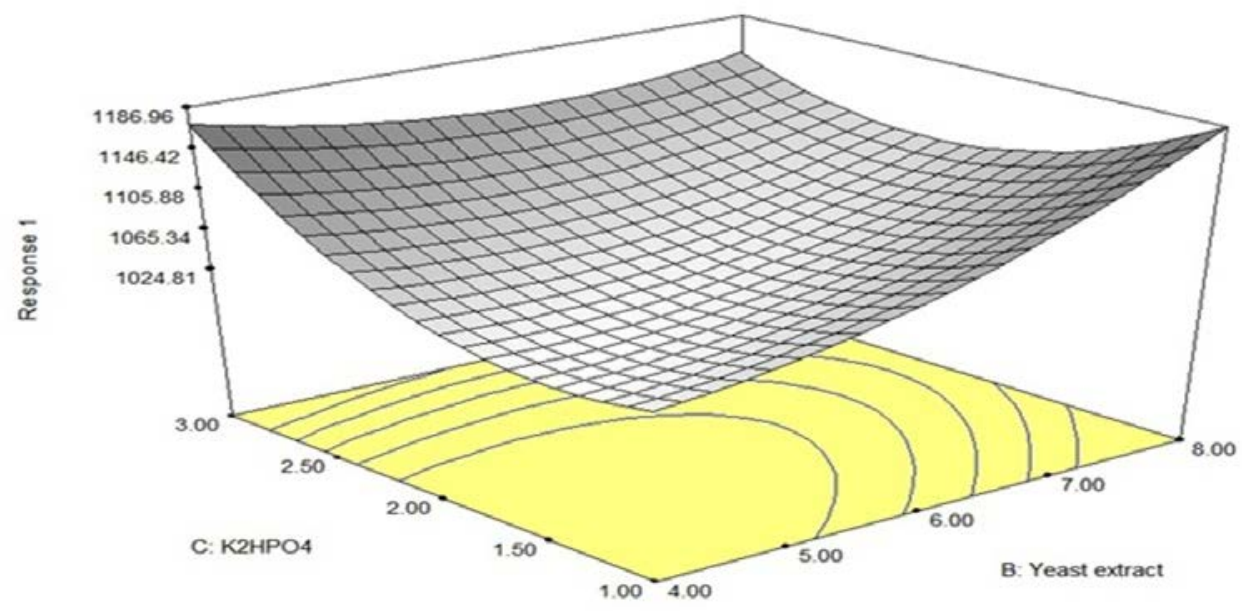

Figure 10. Illustrated the Response Surface Plot for Production of HA; Effect of Yeast Extract and $\mathrm{K}_{2} \mathrm{HPO}_{4}$

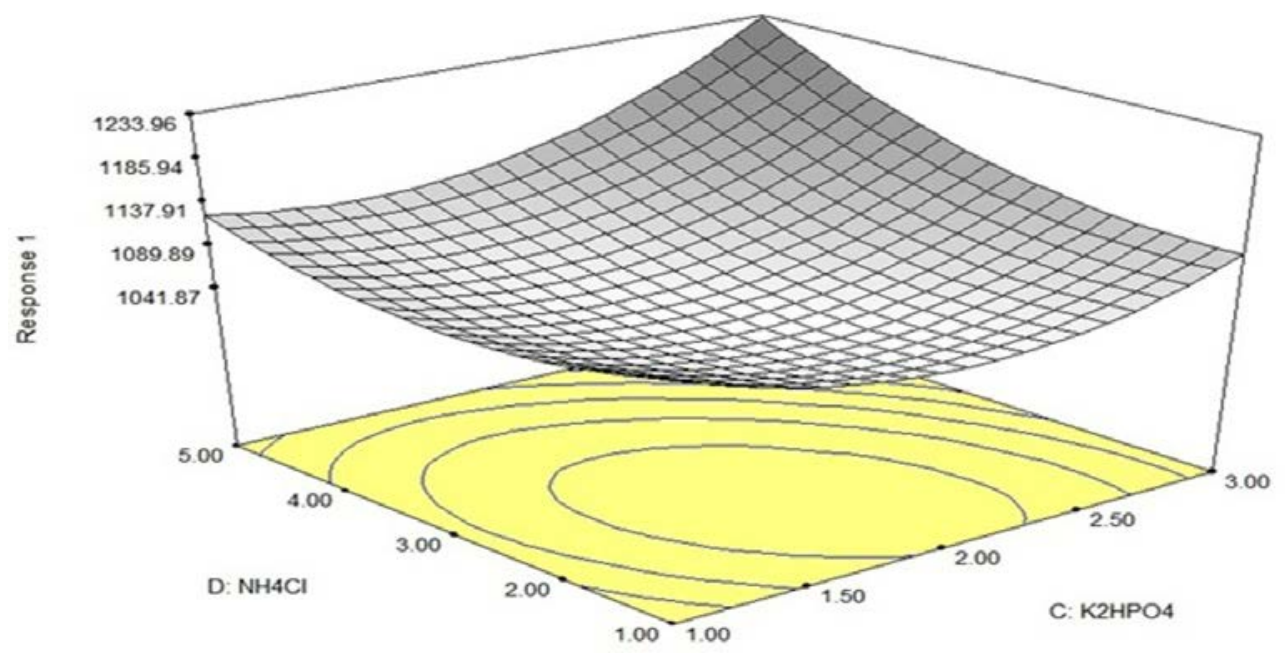

Figure 11. Illustrated the Response Surface Plot for Production of HA; Effect of $\mathrm{NH}_{4} \mathrm{Cl}$ and $\mathrm{K}_{2} \mathrm{HPO}_{4}$ 


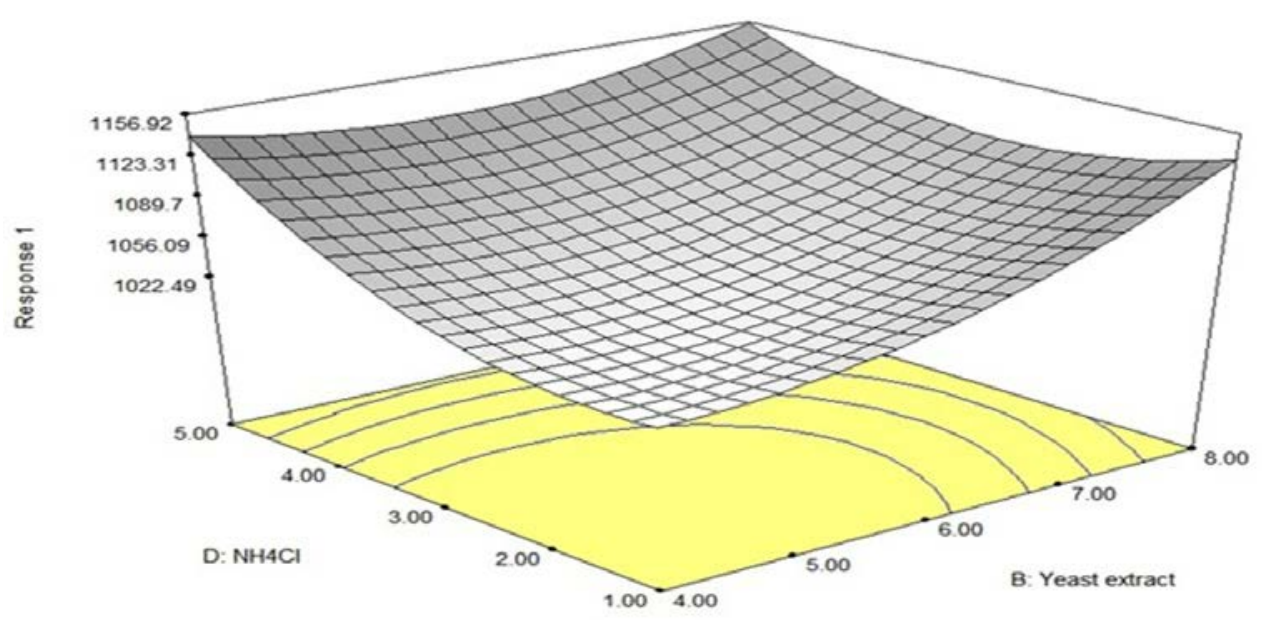

Figure 12. Illustrated the Response Surface Plot for Production of HA; Effect of Yeast Extract and $\mathrm{NH}_{4} \mathrm{Cl}$

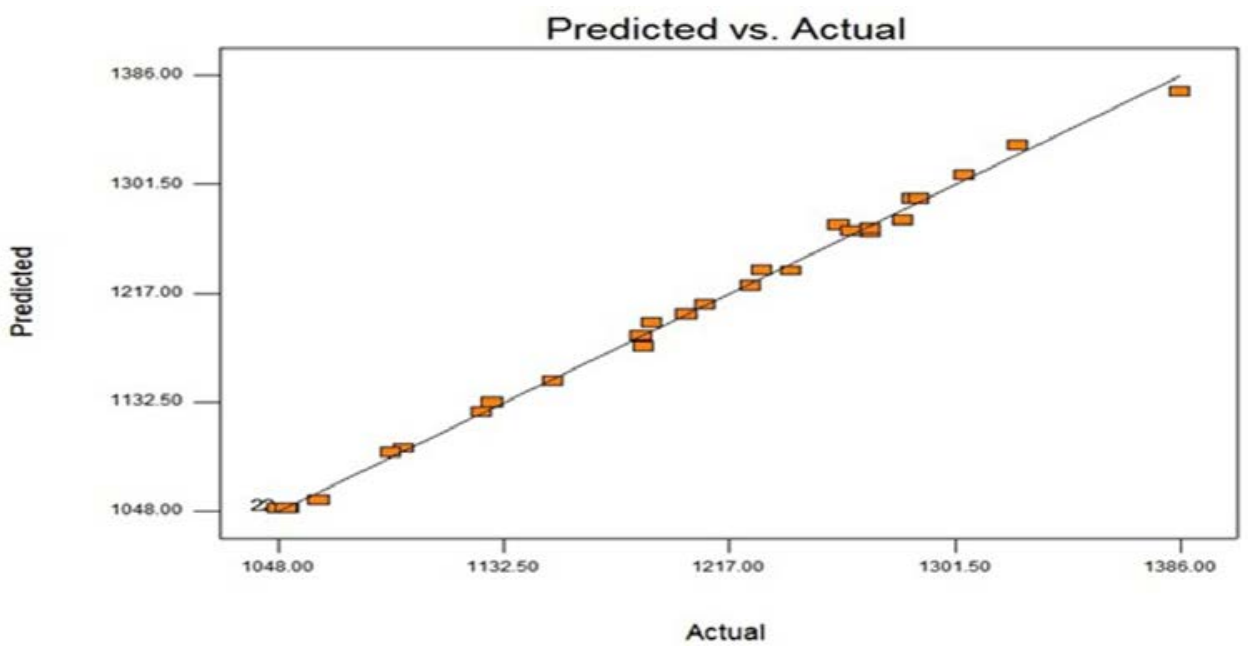

Figure 13. Illustrated the Parity Plot for the Distribution of Predicted and Experimental Values for the Production of HA

\section{Conclusion}

Different types of microbes are known to produce HA [20]. Now a days, fermentative production of HA using cost effective medium has gained an attractive alternative. Different types of Gram-positive and Gram-negative bacteria like Bacillus subtilis [21], Lactococcus lactis [22] and E. coli [23] are also known to produce HA. Among all those Streptococcus equi subsp. Zooepidemicus MTCC 3523 is one of the best producer of HA. Different methods are employed for the production of HA [24]. Liu et al., [25] achieved the over production of hyaluronic acid using Streptococcus zooepidemicus by an intermittent alkaline-stress strategy [26]. Some studies proved the influence of hyaluronidase addition on production of hyaluronic acid by batch fermentation of Streptococcus zooepidemicus [25]. But production ranges are at door steps. Spontaneous mutation results, mutant strain Streptococcus zooepidemicus 3523-7, which produces elevated levels of HA when compared to Streptococcus equi subsp. Zooepidemicus MTCC 3523 grown in Todd Hewitt broth (THB), Brain heart infusion broth (BHI) and Veal infusion broth (VIB). In 1980, Van de Rijn and Kessler used chemically defined medium for the growth and production [11]. The medium is designed for over production of HA and components concentration was determined using taguchi method. The highest 
influencing factors were run in RSM to check the influence of factors concentration on production of HA. 1.4 folds increase in production was achieved using RSM. Finally, 1.76 folds of increase were observed over native medium. The production in this study was appreciable and if run in fermentor under standard conditions this mutant strain will become ideal source for the production of HA. So in future, cost effective media composition for the over production of HA is desirable at large scale fermentation using mutant strain Streptococcus zooepidemicus 3523-7.

\section{Acknowledgments}

The authors are thankful to Prof. J. Srinivasa Rao, Head of the department of Chemical Engineering, Bapatla, for his technical help throughout the work. The authors are also thankful to Management of Bapatla Engineering College, Bapatla for providing the infrastructure facility to carry out the work.

\section{References}

[1] A. Pendleton, N. Arden, M. Dougados, M. Doherty, B. Bannwarth, J. W. Bijlsma, F. Cluzeau, C. Cooper, P. A. Dieppe, K. P. Gunther, H. J. Hauselmann, G. Herrero- Beaumont, P. M. Kaklamanis, B. Leeb, M. Lequesne, S. Lohmander, B. Mazieres, E. M. Mola, K. Pavelka, U. Serni, B. Swoboda, A. A. Verbruggen, G. Weseloh and I. Zimmermann-Gorska, "EULAR recommendations for the management of knee osteoarthritis", report of a task force of the Standing Committee for International Clinical Studies Including Therapeutic Trials (ESCISIT). Ann Rheum Dis., vol. 59, (2000), pp. 936-44.

[2] J. Van Brunt, "More to hyaluronic acid than meets the eye", Biotechnology, vol. 4, no. 9, (1986), pp. 780-782.

[3] A. Shiedlin, R. Bigelow, W. Christopher, S. Arbabi, L. Yang, R. V. Maier, N. Wainwright, A. Childs and R. J. Miller, "Evaluation of hyaluronan from different sources Streptococcus zooepidemicus, rooster comb, bovine vitreous, and human umbilical cord”, Biomacromol, vol. 5, (2004), pp. 2122-2127.

[4] T. Yamada and T. Kawasaki, "Microbial synthesis of hyaluronan and chitin: new approaches”, J Biosci Bioeng., vol. 99, (2005), pp. 521-528.

[5] D. C. Armstrong and M. R. Johns, "Culture conditions affect the molecular weight properties of hyaluronic acid produced by Streptococcus zooepidemicus” Appl. Environ. Microbiol., vol. 63, no. 7, (1997), pp. 2759-2764.

[6] J.-H. Kim, S.-J. Yoo, D.-K. Oh, Y.-G. Kweon, D.-W. Park, C.-H. Lee and G.-H. Gil, "Selection of a Streptococcus equi mutant and optimization of culture conditions for the production of high molecular weight hyaluronic acid”, Enzyme Microb Technol., vol. 19, no. 6, (1996), pp. 440-445.

[7] V. Rangaswamy and D. Jain, "An efficient process for production and purification of hyaluronic acid from Streptococcus equi subsp”, zooepidemicus. Biotechnol. Letters, vol. 30, no. 3, (2008), pp. 493-496.

[8] D. A. Swann and J. W. Kuo, "Hyaluronic acid", Byrom, D. (ed) Biomaterials-novel materials from biological sources. Stockton Press, New York, (1991), pp. 286-305.

[9] W. C. Huang, S. J. Chen and T. L. Chen, "Production of hyaluronic acid by repeated batch fermentation”, Biochem Eng J. vol. 40, (2008), pp. 460-464.

[10] T. Bitter and H. M. Muir, “A modified uronic acid carbazole reaction”, Anal Biochem., vol. 4, no. 4, (1962), pp. 330-334.

[11] I. Van de Rijn and R. E. Kessler, "Growth characteristics of group a streptococci in a new chemically defined medium”, Infect. Immun., vol. 27, no. 2, (1980), pp. 444-448.

[12] J. Zhang, X. Ding, L. Yang and Z. Kong, "A serum-free medium for colony growth and hyaluronic acid production by Streptococcus zooepidemicus NJUST01”, Applied Microbiology and Biotechnology, vol. 72, no. 1, (2006), pp. 168-172.

[13] J. H. Im, J. M. Song, J. H. Kang and D. J. Kang, "Optimization of medium components for highmolecular-weight hyaluronic acid production by Streptococcus sp. ID9102 via a statistical approach”, Journal of Industrial Microbiology and Biotechnology, vol. 36, no. 11, (2009), pp. 1337-1344.

[14] B. F. Chong, L. M. Blank, R. McLaughlin and L. Nielsen, “Microbial hyaluronic acid production”, Appl Microbiol Biotechnol, vol. 66, pp. 341-351, (2005).

[15] D. C. Armstrong and M. R. Johns, "Effect of culture conditions on molecular weight of hyaluronic acid produced by Streptococcus zooepidemicus”, Appl Env Microbiol., vol. 63, no. 7, (1997), pp. 2759-2764.

[16] G.-Y. Lee, S.-J. Ha, J.-H. Jung, D.-H. Seo, J.-Y. Park, S.-R. Kim, N.-W. Park, D.-K. Kweon, S.-H. Park and C.-S. Park, "Effect of non-animal-derived nitrogen sources on the production of hyaluronic acid by Streptococcus sp. KL0188”, Journal of the Korean Society for Applied Biological Chemistry, vol. 52, no. 3, (2009), pp. 283-289. 
[17] Y. H. Chen, J. Li, L. Liu, H. Z. Liu and Q. Wang, "Optimization of flask culture medium and conditions for hyaluronic acid production by a Streptococcus equisimilis mutant nc2168”, Braz J Microbiol., vol. 43, no. 4, (2012), pp. 1553-61.

[18] J. A. Vazquez, M. I. Montemayor, J. Fraguas and M. A. Murado, "Hyaluronic acid production by Streptococcus zooepidemicus in marine by-products media from mussel processing wastewaters and tuna peptone viscera”, Microb Cell Fact, vol. 9, no. 1, (2010), pp. 46.

[19] L. Liu, Y. Liu, J. Li, G. Du and J. Chen, "Microbial production of hyaluronic acid: current state, challenges, and perspectives”, Microbial Cell Factories, vol. 10, no. 99, (2011).

[20] B. Fong Chong, L. M. Blank, R. Mclaughlin and L. K. Nielsen, "Microbial hyaluronic acid production”, Appl Microbiol Biotechnol., vol. 66, (2005), pp. 341-351.

[21] L. J. Chien and C. K. Lee, "Enhanced hyaluronic acid production in Bacillus subtilis by coexpressing bacterial haemoglobin”, Biotechnol Prog., vol. 23, (2007), pp. 1017-1022.

[22] L. J. Chien and C. K. Lee, "Hyaluronic acid production by recombinant Lactococcus lactis", Appl Microbiol Biotechnol., vol. 77, (2007), pp. 339-346.

[23] H. M Yu and G. Stephanopoulos, "Metabolic engineering of Escherichia coli for biosynthesis of hyaluronic acid”, Metabolic Eng., vol. 10, (2008), pp. 24-32.

[24] S. J. Kim, S. Y. Park and C. W. Kin, "A novel approach to the production of hyaluronic acid by Streptococcus zooepidemicus”, J Microbiol Biotechnol, vol. 16, (2006), pp. 1849-1855.

[25] L. Liu, G. Du, J. Chen, M. Wang and J. Sun, "Influence of hyaluronidase addition on the production of hyaluronic acid by batch culture of Streptococcus zooepidemicus”, Food Chem., vol. 110, (2008), pp. 923-926.

[26] L. Liu, M. Wang, G. Du and J. Chen, "Enhanced hyaluronic acid production of Streptococcus zooepidemicus by an intermittent alkaline-stress strategy”, Lett Appl Microbiol., vol. 46, (2008), pp. 383-388. 